\title{
Compact Circularly Polarized Slotted Symmetric V slits Microstrip Patch Antennafor ISM Band Applications
}

\author{
Naw Khu Say Wah ${ }^{1}$ and Hla Myo Tun ${ }^{2}$ \\ ${ }^{1,2}$ Department of Electronic Engineering, Yangon Technological University \\ Gyogone, Insein PO, 11011, Yangon, Myanmar \\ Email: nksw.ytu [AT] gmail.com \\ ${ }^{2}$ Department of Electronic Engineering, King Lauk Phya Institute of Technology Myaungmya \\ Myaungmya, Myanmar \\ Email: hlamyotun.ytu [AT] gmail.com
}

\begin{abstract}
This paper presents a short microstrip patch antenna and analyzes its characteristics in simulation and measured ways. The proposed antenna is meant to be used from 2.4 to $2.5 \mathrm{GHz}$ at the resonant frequency of 2.45 GHz Industrial, Science, and Medical (ISM) spectrum. Besides, insert a diagonal slot in the main patch, and two cutting edges with $V$-slitgives the antenna topropagate a circular polarization pattern. The paper aims to start learning a simple C.P.patch antenna supported the basic concept of microstrip antenna theory. A single-feed C.P., truncated corners, and slit and slot methods are employed to model the antenna apart from its parametric study. The substrate material of the developed antenna is $F R-4$, and it's a relative permittivity of 4.4. The antenna incorporates a compactoverall size of $0.389 \lambda_{0} \times 0.389 \lambda_{0} \times 0.013 \lambda_{0}$, where $\lambda_{0}$ is that the corresponding free-space wavelength at 2.45 GHz. FEKO has been used for not only designing the antenna model but also analyzing its performances. Simulated and measured results have reported that the antenna can work in ISM bands $(2.42-2.5 \mathrm{GHz})$ with VSWR<2, low realized gain, and the limited 3-dB axial ratio at $2.45 \mathrm{GHz}$.
\end{abstract}

Keywords - Circular polarization, Microstrip patch antenna, rectangular slot, V-slits, ISM bands

\section{INTRODUCTION}

ISM (Industrial, Scientific, and Medical) band is being designated to Industry, Science and Medical fields then different types of antennas, for example, a microstrip patch antenna, a helical antenna, a dielectric resonat or antenna are used for various applications such as Wi-Fi, Bluetooth, and cordless phone and so on [1]. One of the largest ISM bands applications is wireless networking (Wi-Fi), including IEEE 802.11, laptops, tablet computers, computer printers, cellphones, etc. Some short-range communication devices such as radio control ch annels for UA Vs (d rones), RFID systems for merchandise, wireless surveillance systems, and wild animal tracking systems operate in the ISM frequency bands [2].

Microstrip patch antenna technology has gained a lot of attention from researchers and ind ustrials in the field of high frequency equipment because of their numerous advantages such as light-weight, low maintenance, ease of fab ric ation, and ease of integration in miniaturized circuits. Moreover, the microstrip patch antennahas been u sed for wideband, narrowband, and multiband purposes. These kinds of antennas are mostly used in the applications of wireless communication, radar, some satellite communication, spacecraft [3], wearable devices [4], and medical applications [5], and so on. Antenna polarization, one of the most vital factors in wave propagation between transmitting and receiving antennas, is divided into three types: linear, elliptical, and circular polarizations [6]. In a portable wireless communication system, the demand for circularly polarized microstrip antennas is greater than linearly polarized on es due to its traits of decreasing the power loss in the mis alignment of transmitting and receiving [7-11]. To be an ac curate alignment between transmitting and receiving, each antennastation should be a linear polarized antenna for propag at ing in the same polarization. Some popular circularly polarized microstrip patch antenna for portable/handheld de vices are RFID reader antenna, WLAN, GPS, rectenna for energy harvesting, mobile phone antenna, and so on. Usually, a sing le feed microstrip patch antennagenerates linearly polarized radiation without introducing some pert urbation, $\mathrm{such}$ as making a slit or slot to the antenna patch to excite two orthogonal modes for C.P.radiation. [12-13]. The single-feed microstrip patch antennas are usually more compact as compared to the dual-feed antennas. However, the circularly polarized patch antenna's compact size can be obtained with limited gain, narrow 3-dB A.R. bandwidth, and imped ance bandwidth [14].

In the literature, authors have intensely concentrated on various techniques of generating C.P. radiation of the single - 
feed configuration. In [15], three types of s ingle-feed circularly polarized micros trip patch antennas (diagonal-fed nearly square, truncated-corners square, and square with a diagonal slot) have been studied analytically by employing impedance Green's functions for segments with magnetic wall boundary as well as experimentally. The authors described that the square patch antenna with a diagonal s lot has the largest axial ratio bandwidth among the three antennas reported. In contrast, the minimum VSWR is obtained with a diagonal-fed nearly square patch antenna. In [16], the au th ors have presented that the trimmed slits and its length adjustment upported the microstrip patch antenna with a reduced patch size to perform C.P. radiation at a fixed operating frequency, als o provided a wide C.P. bandwidth and reduced failu re s due to fabrication. In [17], the compact circular polarization(C.P.) operation has been achieved by cutting a cross -slot of unequal arm lengths in a circular microstrip patch or by insetting fournarrow slits of different lengths at the edges of a square microstrip patch. Due to the cross slots perturbation or the narrow slits, the antenna's fundamental resonant mo d e occurs at a lower frequency and is split into two near-degenerate orthogonal modes with equal amplitudes and a 90o phase difference; this results in compact C.P. operation. In [18], a novel design of single-feed equilateral-triangular micros trip antenna for circular polarization (C.P.) has been presented that the single-fed trian gu lar patch can be C.P. antenna by embedding a narrow slot or a cros s-slot of unequal slotlengths in the main patch. Furthermore, circu lar polarization is theoretically possible from a microstrip antenna excited by a single feed if two spatially orthogonal modes are excited in phase quadrature [19].

This paper focuses on a single-fed microstrip patch antenna combined with a diagonal s lot, truncated corners, and Vslits to design a compact C.P. patch antenna with good impedance matching at ISM bands. Still, other limitations such as low gain, narrow bandwidths are taking into account in this model. The main idea of loading V-slits each truncated corner to the main patch is to monitor the $3 \mathrm{~dB}$ axial ratio at $2.45 \mathrm{GHz}$. This paper's remainder is organized as follows: In Section II, the configuration of the proposed antenna, the operating mechanism, and the simulated results are presented. In Section III, the measured and simulated results are discussed. After all, the conclusions are drawn in Section IV.

\section{ANTENA CONFIGURATION AND ANALYSIS}

\subsection{Design of Proposed Antenna}

The proposed antenna configuration is depicted in Fig ure 1. The antenna has been designed on a $1.6 \mathrm{~mm}$ thick-sing le layer FR4 substrate having a relative permittivity of 4.4 with a los s tangent of 0.025 . The total size of the antenna is $47.63 \mathrm{~mm} \times 47.63 \mathrm{~mm} \times 1.6 \mathrm{~mm}$. Basically, the trimmed-corner technique is mostly used for generating circular polarization in a single-fed patch antenna. In our design configuration, we have used a co mbin ation of two corners truncated and symmetric V-shaped slits on a radiating patch to create the minimum $3 \mathrm{~dB}$ axial ratio response at the desired res onant frequency. Moreover, a symmetric V-slit at each truncated corner also extends the current dis trib ution on the main patch to be miniaturized the patch antenna's physical dimension. There are different reasons for loading s lots on the patch antenna. If slots are placed on the patch, that decreases the antenna gain due to metallic size reduction. A slot could also be added to adjust the antenna's input impedance if the antenna's input impedance is far from the characteristic impedance of the cable and the reflection loss is too small. The microstrip line feed effects and a diag onal slot on the main patch provide better impedance matching with $50 \mathrm{ohms}$ coaxial probe feed for the antenna configuration. This feeding method is very widely us ed becauseit is effortles s to design and analyze and easy to manufacture. The overall dimensions of the developed antenna are as described in Table 1.

Table 1. Dimensions of the proposed compactC.P. antenna

\begin{tabular}{llllll}
\hline $\boldsymbol{W}_{\boldsymbol{g}}(\mathbf{m m})$ & $\boldsymbol{L}_{\boldsymbol{g}}(\mathbf{m m})$ & $\boldsymbol{W}_{\boldsymbol{p}}(\mathbf{m m})$ & $\boldsymbol{L}_{\boldsymbol{p}}(\mathbf{m m})$ & $\boldsymbol{C}_{\boldsymbol{w}}(\mathbf{m m})$ & $\boldsymbol{W}_{f}(\mathbf{m m})$ \\
\hline 47.63 & 47.63 & 2 & 27 & 7.07 & 2.88 \\
\hline$V_{w}(\mathbf{m m})$ & $\boldsymbol{V}_{d}(\mathbf{m m})$ & $\boldsymbol{s}_{l}(\mathbf{m m})$ & $\boldsymbol{s}_{w}(\mathbf{m m})$ & $\boldsymbol{L}_{f}(\mathbf{m m})$ & \\
\hline 3.7 & 6.5 & 15.56 & 1.41 & 10.32 & \\
\hline
\end{tabular}




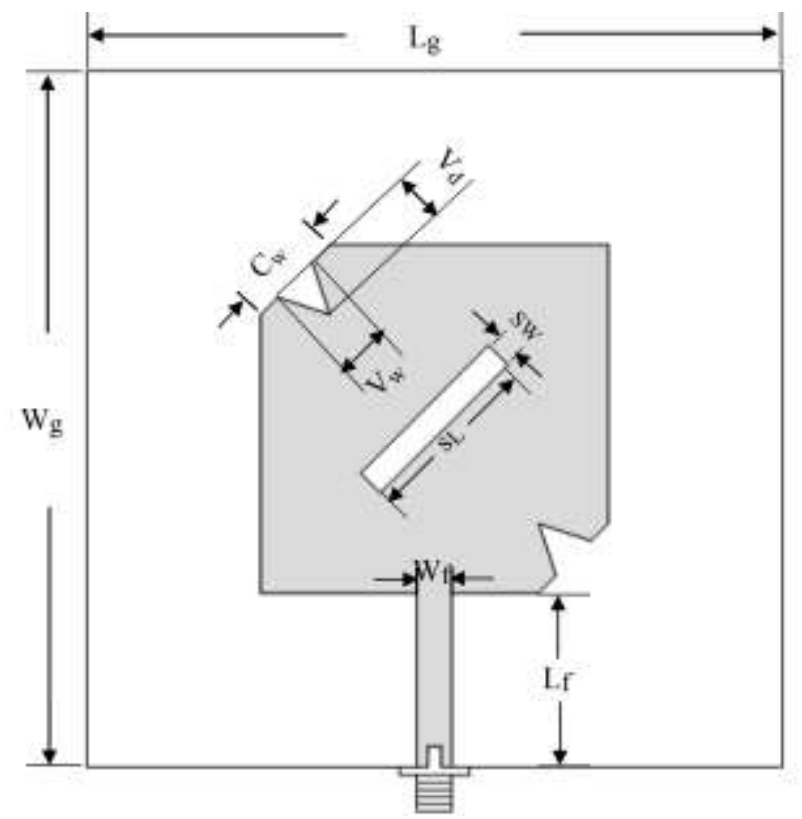

Figure.1. The Geometry of the proposed compact C.P. antenna model

\subsection{Operation Principle}

Initially, a compact microstrip patch antenna without slotand slit, using a square patch of $27 \times 27 \mathrm{~mm}^{2}$ to operate at the resonant frequency $2.45 \mathrm{GHz}$ in ISM bands, has investigated. Fixing the corner-truncated ratio, $5 / 5$ is 1 , the length of the cutting-edge $\mathrm{Cw}$ is $7.07 \mathrm{~mm}$. The trimmed area ratio at two corners of the patch to the total antenna size, $2 \mathrm{~A} / \mathrm{S}$, is 0.034 (3.4\% in size reduction). As shown in Figure 3, the frequency in resonant range shifts to the right of the high er frequency range in performance analysis. According to the trimmed corner's effect at two edges of the patch, it gives wider bandwidth, and the resultant impedance bandwid th of $10 \mathrm{~dB}$ return loss is in the frequency range from 2.5 to 2.7 $\mathrm{GHz}(8.2 \%$ B.W.). According to the C.P. antenna's fundamental principle, the antenna can generate circular polarization by trimming the patch's edges. From the simulation result, we noticed that this compact microstrip patch has an axial ratio of $2.86 \mathrm{~dB}$ at $2.55 \mathrm{GHz}$ with the wider impedance bandwidth from 2.5 to $2.7 \mathrm{GHz}$. Obviously, the antenna design needs some parameter optimization to obtain a good impedance matching at the desired frequency of $2.45 \mathrm{GHz}$ and better A.R. result in its performance. Besides, our major consideration is size miniaturization and introducing the V-s lits and a diagonal sot in the design configuration to achieve a compact C.P. antenna at the desired frequency.

Next, the single-feed corner-truncated C.P. microstrip patch antenna has been modified by lo ading a slot diagonally at the patch's center. Its characteristics havebeen discussed in simulation approaches. The depiction of compact anten na models with and without slot is shown in Figure 2. The dimension of the rectangular slot sw $\mathrm{sL}$ is $1.41 \times 15.56 \mathrm{~mm}^{2}$. Adding a slot into the main patch makes more decrease the antenna size in the ratio of $\mathrm{As} / \mathrm{S}^{\prime}$ is $0.182(18 \%$ reduction in size). The patch's properties' significant variation with the slot is that the frequency is moving to the left, the lower frequency span, and its return loss is better at $2.4 \mathrm{GHz}$ and $2.65 \mathrm{GHz}$, which is a merit of the configuration. It could be realized from Figure 3 that at $2.42 \mathrm{GHz}$, the return loss is about $-13 \mathrm{~dB}$, and at $2.65 \mathrm{GHz}$, the return loss is about -16.4 $\mathrm{dB}$, respectively. However, in surface current excitation, a s mall number of electric currents canceled each other a ro und the slot's edge. It affects the axial ratio to go higher than $3 \mathrm{~dB}$, and consequently, the antenna loses its circular polarization radiation.

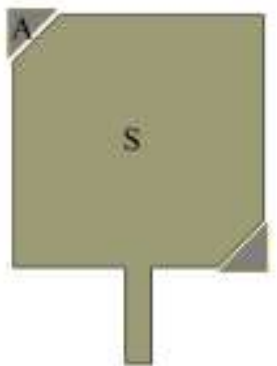

(i)

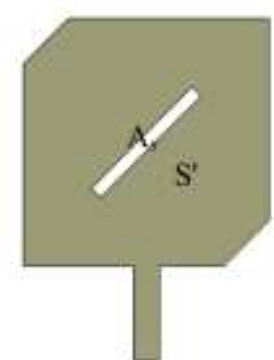

(ii)

Figure.2. The single-fed corners-truncated patch model (i) without slot (ii) with slot 
For the last configuration, adding a new idea of molding symmetric V-s lit at each of the corners-truncated ed ge s of the slotted patch and each V-slit is formed by extracting a small triangularpatch from the main patch. It is noticed that the V-s lit's vertexand width can able to control the axial ratio and reflection coefficient of the anten na. The res ultant antenna model is shown in Figure 1, and its model in the simulation window can see in Figure 5. Figures 3 and 4 demons trate the comparisons of simulated $\left|\mathrm{S}_{11}\right|$ and the axial ratio between the antenna's three different geometry.

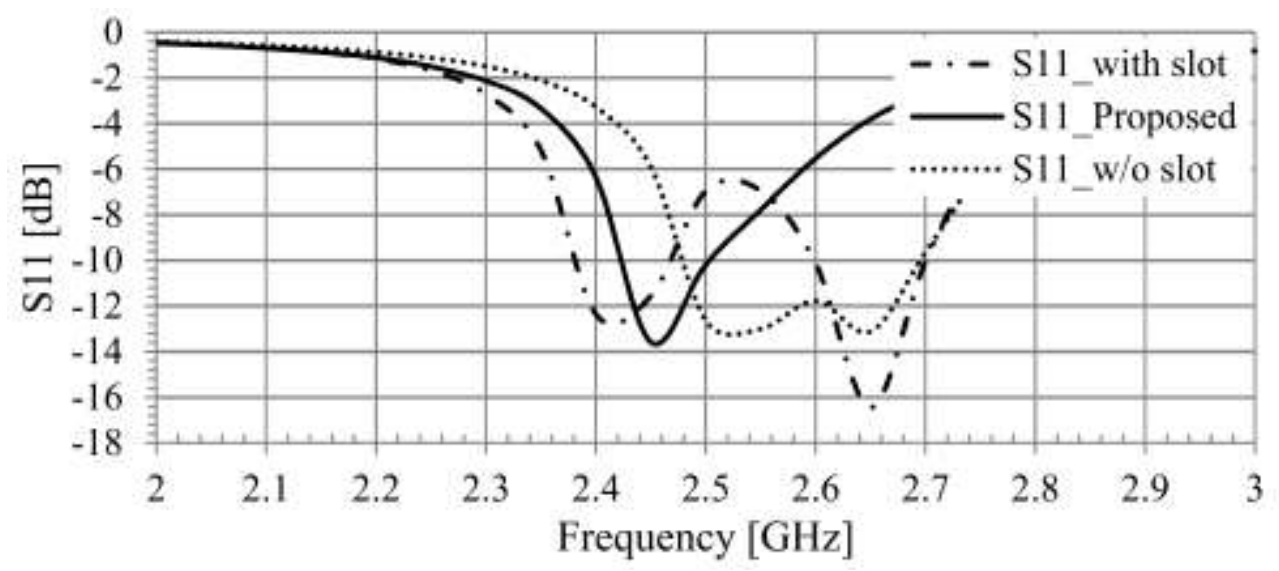

Figure.3. A comparis on of $\left|\mathrm{S}_{11}\right|$ between three different layouts of antenna

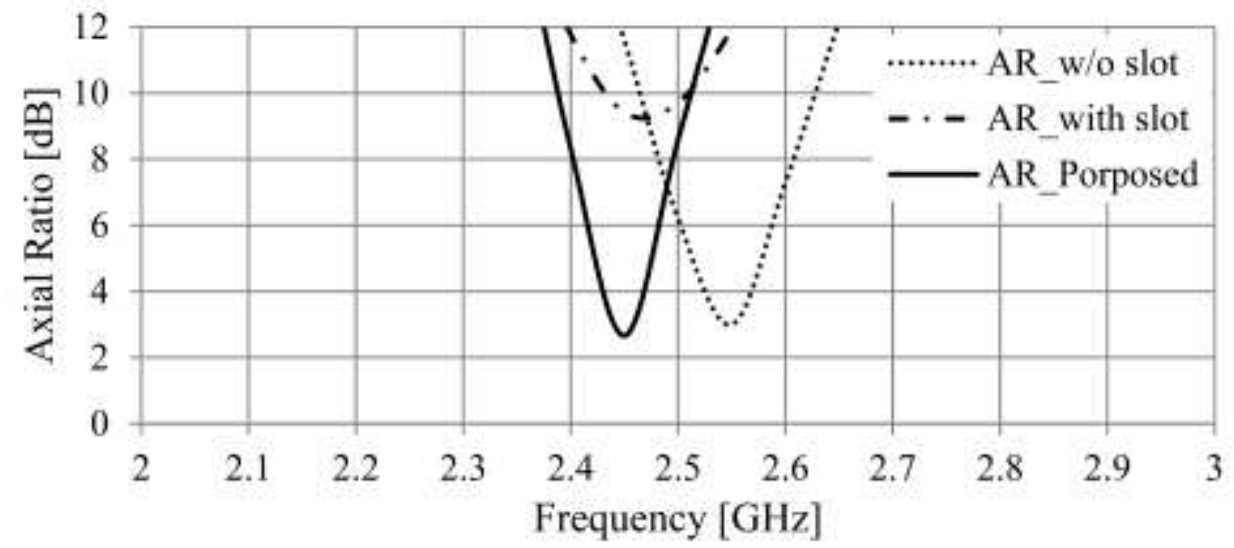

Figure.4. A comparis on axial ratio between three different layouts of antenna

\section{SIMULATED AND MEASURED RESULTS}

The antenna prototype has experimented and then meas ured results were compared with simulation results. Fig u re 6 illustrates the comparison of the simulated and measured $\left|\mathrm{S}_{11}\right|$. Good agreement is found between simulated and measured results of the reflection coefficient, except for a small frequency shift, probably due to the fabrication tolerances. From the simulated results, we found that the propos ed antenna gives the reflection coefficient $\left|\mathrm{S}_{11}\right|$ between the frequency range from $2.42 \mathrm{GHz}$ to $2.5 \mathrm{GHz}$, and its response is sharpened at $2.45 \mathrm{GHz}$ of $14 \mathrm{~dB}$. In the meantime, the measured impedance bandwidths or $\left|\mathrm{S}_{11}\right|$ less than $10 \mathrm{~dB}$ is from $2.43 \mathrm{GHz}$ to $2.54 \mathrm{GHz}(5 \%)$, thus satis fying the ISM bands applications from 2.4 to $2.5 \mathrm{GHz}$.

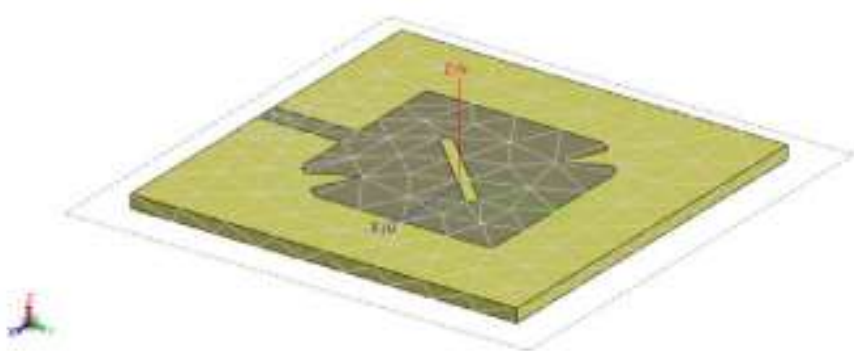

Figure.5. The proposed antenna in FEKO electromagnetic simulator 


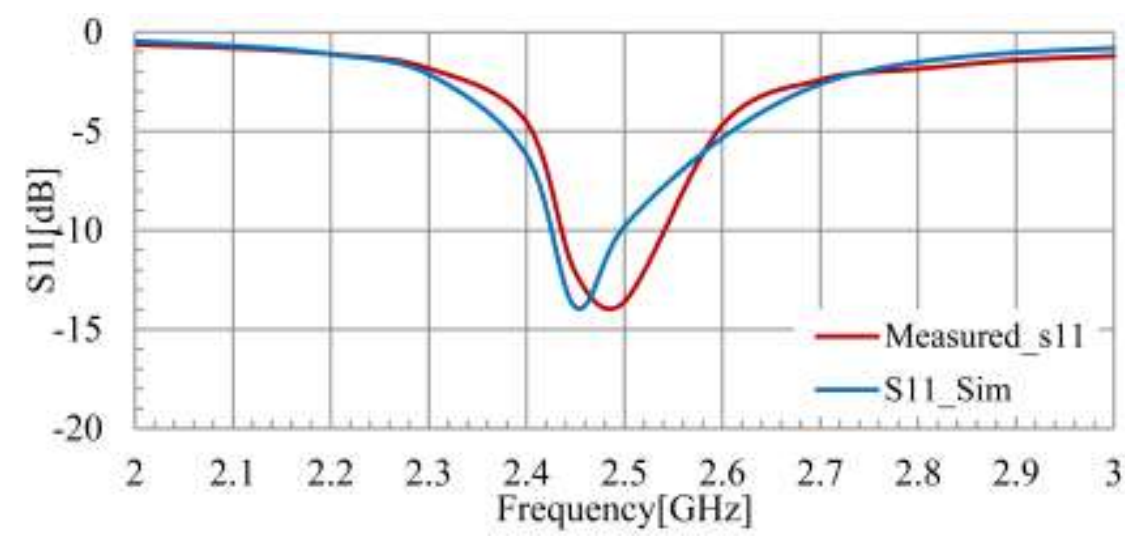

Figure.6. Measured and simulated $\left|\mathrm{S}_{11}\right|$ versus frequency

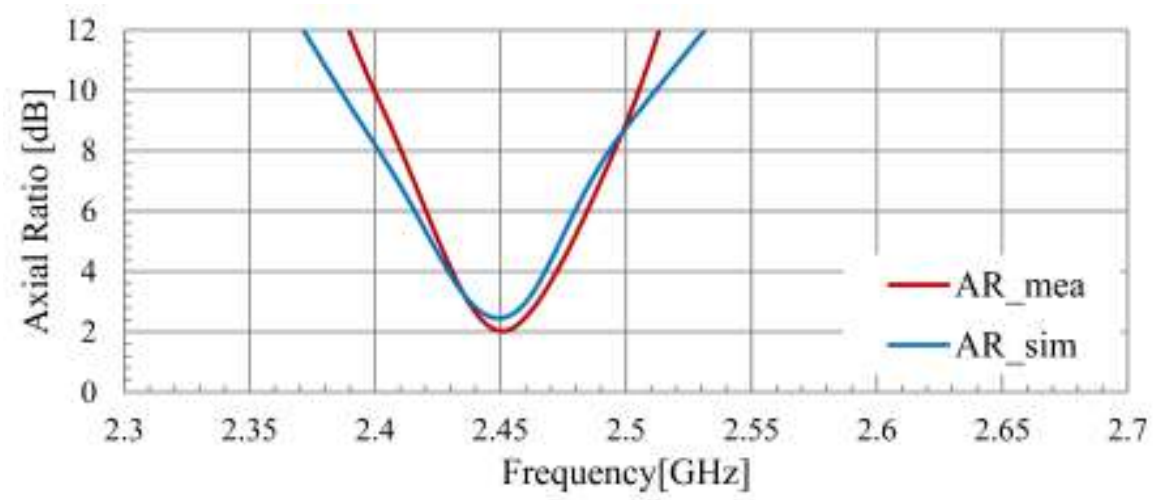

Figure.7. Measured and simulated axial ratio versus frequency

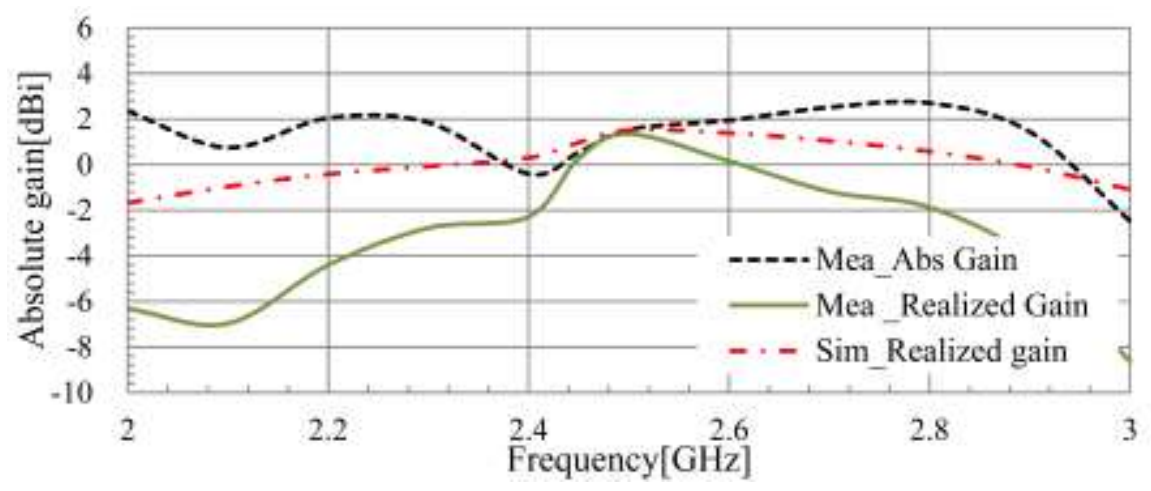

Figure.8. Measured and simulated gain versus frequency
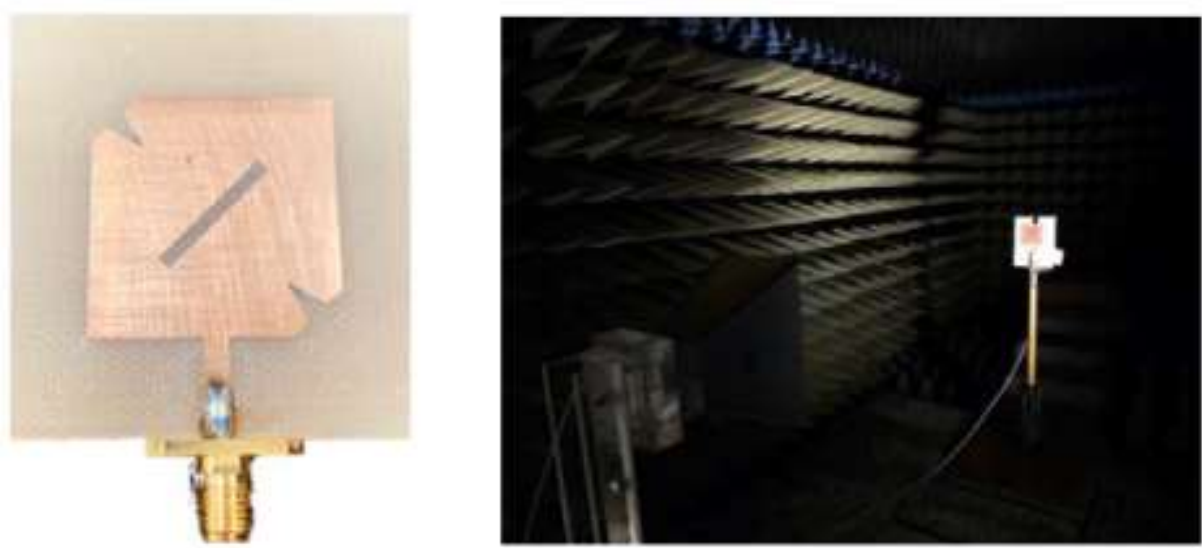

Figure.9. (a) Fabricated antenna prototype (b) Measurement of the antenna in the anechoic chamber 
The distribution of current and the radiation pattern of the antenna are discussed by simulation. Fig 10 shows the simulation results of the current distribution of the antenna surface.
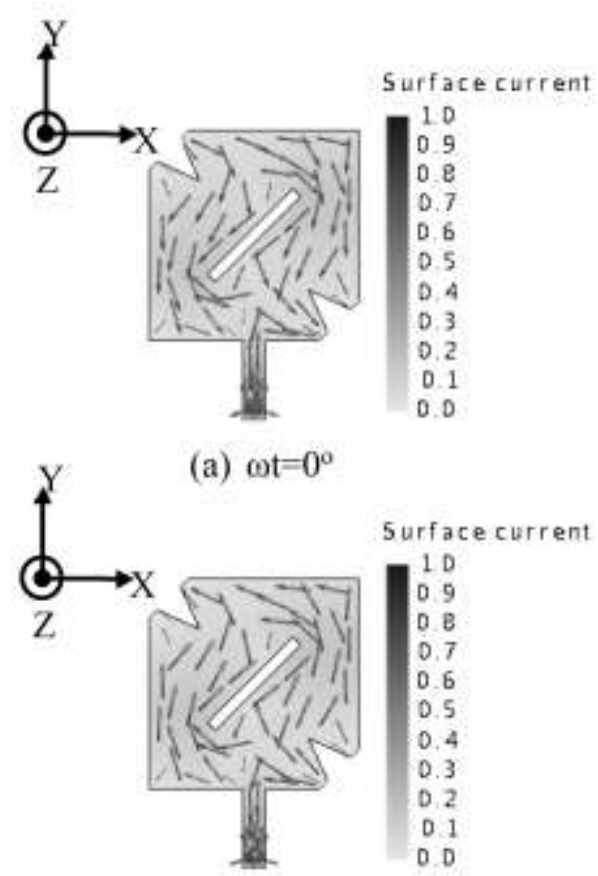

(c) $\omega t=180^{\circ}$

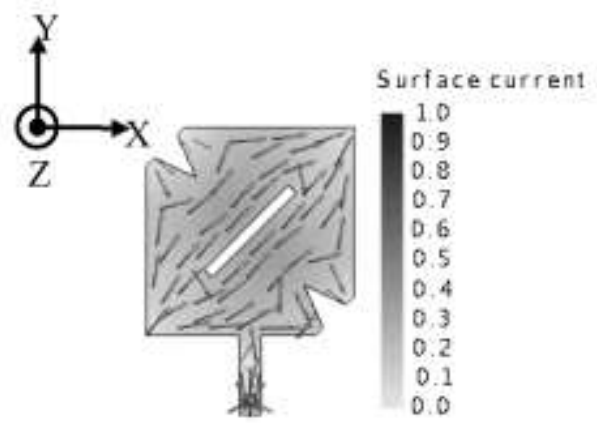

(b) $\omega t=90^{\circ}$

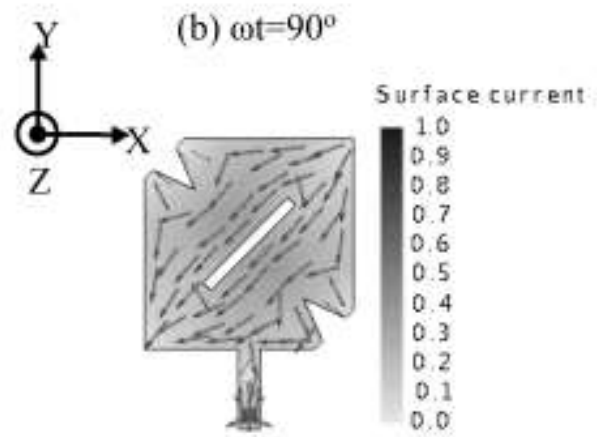

(d) $\omega \mathrm{t}=270^{\circ}$

Figure.10. Surface current dis tributions at $2.45 \mathrm{GHz}$ with different time phases (a) $0^{\circ}$ (b) $90^{\circ}$ (c) $180^{\circ}$ (d) $270^{\circ}$

In Figure 10 (a) and (c), the current flowing fromone radiating edge to another radiating edge takes a lon ger patch from around the diagonal slot due to the patch's slot-loading. Due to this longer current path, there is a shift in the antenna's resonant frequency that leads to antenna miniaturization. Besides, it is observed that the non-uniformly excitation of surface electric currents close to the s lot causes field cancelation: this can affect the 3-dB axial ratio quality and give higher cross-polarization in radiation. FromFigure 10 (b) and (d), the radiating patch has a straight flow of current from one radiating edge to another radiating edge. To comprehend the antenna C.P. operation's sense, the current distributions at $2.45 \mathrm{GHz}$ on the radiating patch of the proposed antenna in XY-plane for different phase angles are studied. These four subplots depict the surface current vectors at different time phases $(\omega \mathrm{t})$ from $0^{\circ}, 90^{\circ}, 180^{\circ}$, and $270^{\circ}$ with an interval of $90^{\circ}$. It is expected fromthe current dis tribution that asymmetry in the antenna structurecan rotate the current that leads to C.P. radiation.

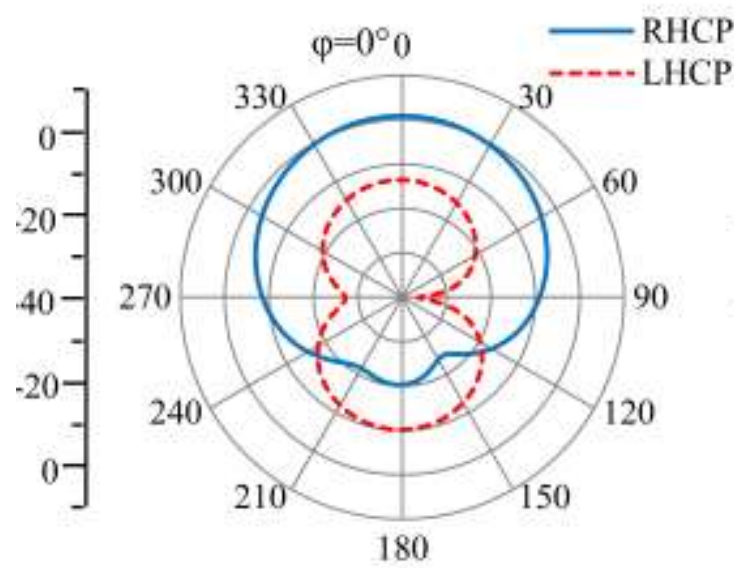

(a)

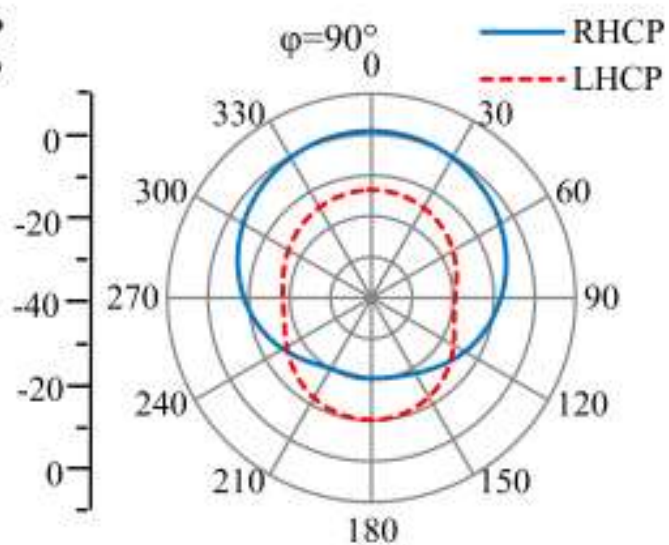

(b)

Figure.11. Simulated radiation patterns of the proposed compact C.P. antennaat 2.45 GHz: (a) XZ-plane and (b) YZplane 


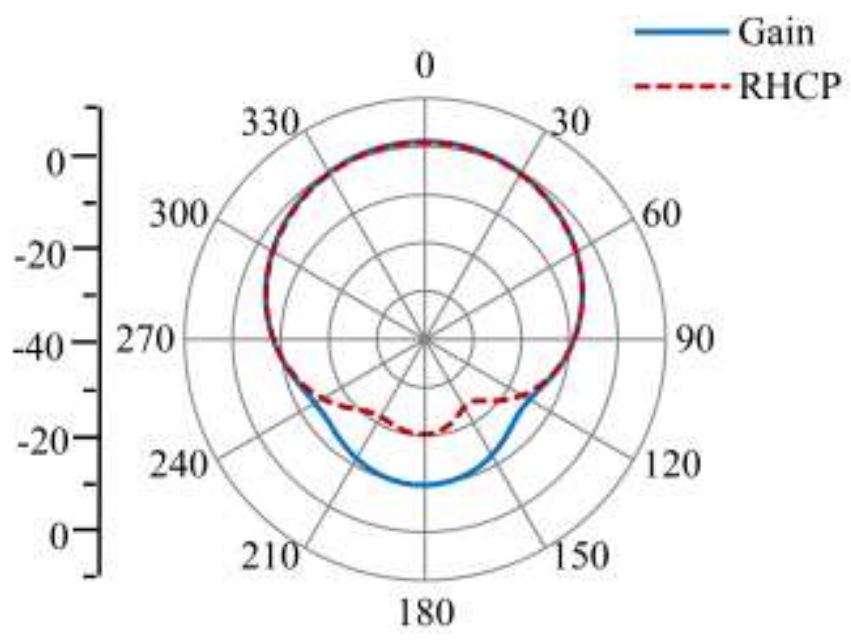

Figure.12. Simulated Gain patterns of the antenna at $2.45 \mathrm{GHz}$

Moreover, the patch's current excitations are anticlockwise, which means the antenna works in RHCP mode. The simulated radiation patterns in both X.Z.- and YZ-plane are illustrated in Figure 11. It is obs erved th at the proposed antenna generates a good RHCP radiation in broadside direction with signs of radiation dissipation lo wer th an $-10 \mathrm{~dB}$. The level of cros s-polarization, LHCP radiation could be further improved with slight modification in the perturb ation geometry loaded on the radiating patch. There has no beamas ymmetry or tilt in the radiation patterns due to symmetry in feed structure. The proposed single-fed antenna gives simulated peak gain and RHCP gain of $0.97 \mathrm{~dB}$ and $0.87 \mathrm{~dB}$; moreover; it generates right-hand circular polarization in its radiation characteristics, as shown in Figure 12.

\section{CONCLUSION}

A $2.45 \mathrm{GHz}$ compact circularly polarized single-fed directional microstrip patch antenna for ISM frequency band applications is proposed and fabricated. The proposed antenna consists of a trimmed-edge square $\mathrm{p}$ atch lo aded with a diagonal slotand V-s lits in its design layout. Inserting a diagonal slot and a pair of V-slits at each trimmed e dge were utilized to improve the antenna's axial ratio and impedance matching. The size of the antenna is $47.63 \mathrm{~mm} \times 47.63$

$\mathrm{mm} \times 1.6 \mathrm{~mm}$. The simulation results showed that the compactC.P. antenna satisfied the port reflection coefficient $\left|\mathrm{S}_{11}\right|$ $<-10 \mathrm{~dB}$ in the $2.42 \sim 2.5 \mathrm{GHz}$, realized gain of $0.87 \mathrm{~dB}$, and the minimum 3-dB axial ratio of $2.45 \mathrm{~dB}$ at the resonant

frequency of $2.45 \mathrm{GHz}$. In antenna measurement, the measured $\mid \mathrm{S}_{11} \mathrm{I}_{\text {band width, 3-dB axial ratio bandwidth and realized }}$ gain were $2.43-2.54 \mathrm{GHz}(5 \%), 2.438-2.465 \mathrm{GHz}(1.1 \%)$, and $0.3 \mathrm{~dB}$. We have found that the proposed compact C.P. directional antenna meets the qualification of planar and compact ability in its design. It can also be said that the simulated and measured results are in good agreement despite the shift in the resonant peak value, which may be due to the effect of the soldering of the SMA and connecting cable los ses during meas urement. Possibly, the losses of conductor as sociated with the microstrip feed line that experienced the antenna gain drops of $0.57 \mathrm{~dB}$ from the simulated result. By properly tuning the dimensions of slot and slits with simulation software, the proposed design with relatively high gain, a wider 3-dB axial ratio bandwidth, would be obtained.

\section{ACKNOWLEDGEMENT}

The authors especially thank Mr.Takafumi FUJIMOTO, As sociate Professor of Nagasaki University in Japan, for his guidance and lectures on the short-termantenna measurement systemcourse. The authors acknowledge all the teachers in the Electronic Engineering Department at Yangon Technological University for their valuable suggestions and encouragementduring this paper's preparation.

\section{REFERENCES}

[1] Neha Minhas et al., 2017. "Performance Analysis of ISM Band Antennas: A Survey," International Journal of Advanced Research in Computer Science, 8 (8):371-375.

[2] https://en.wikipedia.org/wiki/ISM_band.

[3] P. K. Jhala, S.S. Kashyap, and P. M. Paneliya. 2015. "Microstrip Antenna for ISM Band (2.4GHz) Applic ation s-A review," International Journal of Advanced Information Science and Technology 4(4), ISSN: 2319:2682.

[4] M. F. Ismail, M. K. A. Rahim, E. I. S. Saadon, and M. S. Mohd. 2014. "Compact circularly polarized textile antenna," in Wireless Technology and Applications (ISWTA), 2014 IEEE Symposium: 134-136. 
[5] Changrong Liu, IEEE, Yong-Xin Guo, and Shaoqiu Xiao.2014. "Circularly Polarized Helical Antenna for ISM-Band Inges tible Capsule Endoscope Systems," IEEE Tran sactions on Antennas and Propagation 62 (12): 6027-6039.

[6] H. J. Visser. 2006. “Array and phased array antennabasics,” John Wiley \& Sons.6

[7] Farswan, A et al. 2106."Design of Koch fractal circularly polarized antenna for handheld UHF RFID reader applications," IEEE Trans actions on Antennas and Propagation 64 (2), 771-75.

[8] Hegyi, B., and J. Levendovszky. 2010. "Enhancing the performance of medical implant commun ic ation Systems through cooperative diversity," International Journal of Telemedicine and Applications: 1-10 (Article ID 920704).

[9] Rappaport, T. S., and D. A. Hawbaker. 1992. "Wideband microwave propagation parameters using circular and linear polarized antennas for indoor wireless channels," IEEE Trans actions on Communications 40 (2):240-45.

[10] Singh, A. K., R. K. Gangwar, and B. K. Kanaujia. 2016. "Circularly polarized annular ring microstrip antenna for high gain application,"Electromagnetics 36(6):379-91.

[11] Yang, P., S. He, Y. Li, and L. Jiang. 2012. "Low-profile microstrip antenna with bandwidth enhancementfor radio frequency identification applications," Electromagnetics 32 (4): 244-53.

[12] Nasimuddin, Z. N. Chen, and X. Qing. 2010. "Asymmetric-circular-shaped slotted microstrip antennas for circular polarization and RFID applications," IEEE Trans actions on Antennas and Propagation 58 (12): 3821-3828.

[13] X.Qing and Z. N.Chen. 2011. "Compact asymmetric-slit microstrip antennas for circular polarization," IEEE Trans actions on Antennas and Propagation 59(1): 285-288.

[14] Shas hi Kant Pandey, Ganga Prasad Pandey, and P. M. Sarun. 2019. Circularly polarized micro s trip an ten na with fractal trees loaded ground plane, Electromagnetics 39(7): 505-523.

[15] Sharma, P. C., and K. C. Gupta. 1983. "Analysis and optimized design of single feed circularly polarized microstrip antennas," IEEE Transactions and Antennas Propagation 31,949-955.

[16] K.L.Wong and J.Y. Wu. 1997. "Single-feed small circularly polarized squaremicrostrip antenna," Electron Lett 33, 1833-1834.

[17] W.S. Chen, C.K. Wu, and K.L. Wong. 1998. “Compact circularly polarized circular microstrip antenna with cross slot and peripheral cuts," Electron Lett 34, 1040-1041.

[18] J.-H. Lu, C.-L. Tang and K.-L. Wong. 1999. "Single-feed slotted equilateral-triangular microstrip antenna for circular polarization," IEEE Transactions on antennas and propagation 47 (7), 1174-1178.

[19] Prof Umar Farooq, Engr. M. Javid Asad, Dr. Habibullah Jamal. 2003. "Design of Circularly Polarized Square Microstrip Patch Antenna," Proceeding s IEEE INMIC, pp. 228-231. 